\title{
In Memoriam: Dr. Alberto Gyhra Soto
} (1942-2020)

\author{
Emilio Alarcón ${ }^{1,2}$, Roberto González. ${ }^{1,2}$ \\ 1 Departamento de Cirugía, Facultad de Medicina, Universidad de Concepción. \\ 2 Hospital Clínico Regional "Dr. Guillermo Grant Benavente" de Concepción.
}

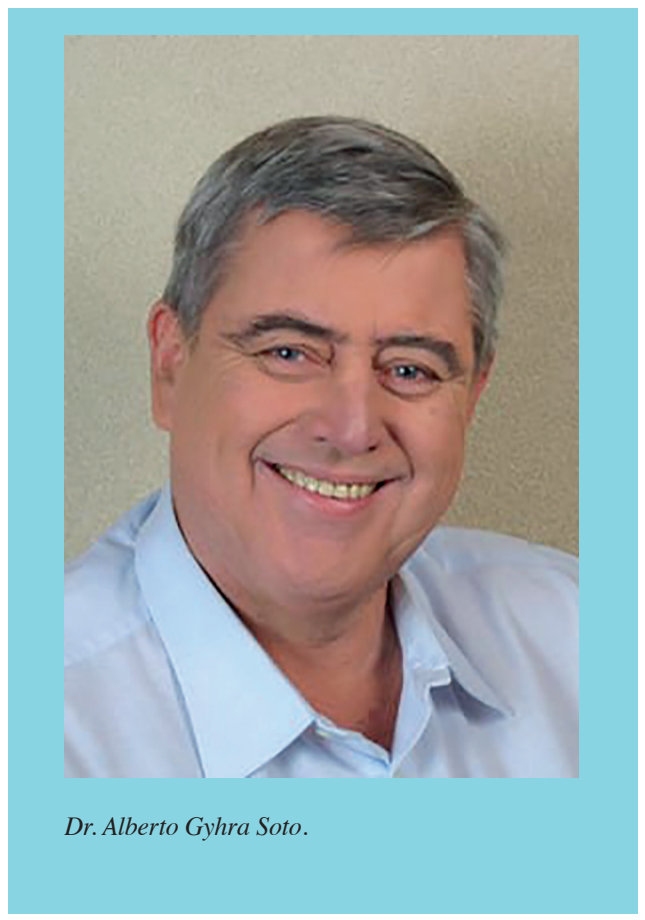

Ha fallecido el Dr. Alberto Gyhra Soto, Profesor Emérito de Cirugía de la Universidad de Concepción, y quien fuera Presidente de la Sociedad de Cirujanos de Chile, Presidente del Capítulo Chileno del American College of Surgeons, y Alcalde de la ciudad de Quillón, entre otros destacados cargos.

En 1970 obtuvo una beca de perfeccionamiento en Cirugía Cardiotorácica en Bruselas, Bélgica. A su regreso inició un proyecto de Cooperación y Asistencia Técnica entre el gobierno belga y el Ministerio de Salud de Chile. Se propuso la creación de una Unidad Coronaria y una unidad de reanimación, y se programó para septiembre de 1973 una reunión de la Comisión mixta Chileno - Belga que debería aprobar el proyecto de cooperación. Dada la contingencia chilena de aquella época, dicha reunión no pude llevarse a cabo, pero a pesar de estas dificultades, y gracias al apoyo incondicional de la Universidad de Concepción, que financió insumos y equipos, el Dr. Gyhra inició un programa de entrenamiento en cirugía experimental que permitió afinar detalles para una primera cirugía cardíaca en Concepción. 
El 14 de noviembre de 1974 realizó la primera cirugía cardíaca con circulación extracorpórea en el Hospital Clínico "Dr. Guillermo Grant Benavente” de Concepción. Se trató de una comunicación inter auricular cuyo cierre fue exitoso. Utilizó un oxigenador Travenol ${ }^{\circledR}$, un intercambiador de calor no desechable y monitores de la década del ' 50 .

En los años que siguieron, gracias al esfuerzo y persistencia del Dr. Gyhra, se inauguró en el Hospital la Unidad de Reanimación de Cirugía Cardio-Torácica (la "Sala 20") y se realizaron ocho intervenciones con circulación extracorpórea entre 1974 y 1977 . Estos logros entusiasmaron a las autoridades universitarias y regionales, pero el Ministerio de Salud central no apoyó estas iniciativas y el año 1977 intentó prohibir la cirugía cardíaca en Concepción.

Sin el respaldo ministerial, el Dr. Gyhra buscó nuevos apoyos, y el año 1976 presentó a CONICYT un proyecto para desarrollar un "Centro Médico-Quirúrgico Torácico y Cardiovascular en la VIII Región de Chile”, proyecto que fue presentado a la Embajada de Francia. La idea del proyecto era desarrollar no solo la cirugía Cardio-Torácica, sino también la hemodinamia, la radiología, crear una unidad coronaria y todos los aspectos relacionados con la especialidad. El proyecto tenía una fuerte vocación asistencial y docente, tanto para la formación de pre y postgrado, como para la creación de conocimiento a través de la investigación. Gracias al proyecto de cooperación se realizaron becas de perfeccionamiento, visitas de expertos franceses y programas de capacitación y educación para médicos, enfermeras y kinesiólogos.

Paralelamente al trabajo clínico, la actividad en la Universidad permitió mejorar el nivel de enseñanza de pre y post grado. Además, en forma desinteresada, generosa e incondicional, el Dr. Gyhra apoyó el desarrollo de la cirugía cardíaca en Temuco, no solo con apoyo técnico y académico sino incluso con el préstamo indefinido de equipos tan relevantes como la máquina de circulación extracorpórea.

Muchos conceptos lo pueden definir: académico, investigador, innovador, visionario, inspirador, regionalista, servidor público, generoso; pero la que mejor lo define es "Maestro", que entre sus acepciones está: "una persona que enseña una ciencia, arte u oficio, de mérito relevante entre los de su clase" o "un grado simbólico, jerárquico, relacionado con la trascendencia después de la muerte".

Qué duda cabe; la cirugía de Chile pierde un Maestro que marca y trasciende. Todos los que aprendimos y que seguimos el camino que él inició con tanto esfuerzo y perseverancia le agradecemos.

Querido Dr. Gyhra, le extrañaremos, que descanse en paz. 